\title{
Effect of non-stoichiometry and Ce-doping on the tetragonal superconducting phase $\mathrm{CaBaLaCu} \mathrm{O}_{7-\delta}$
}

\author{
I K GOPALAKRISHNAN, R ALFRED GUNASEKARAN, \\ J V YAKHMI and R M IYER \\ Chemical Group, Bhabha Atomic Research Centre, Trombay, Bombay 400085, India
}

\begin{abstract}
We have synthesized $\mathrm{CaBaLaCu}_{3} \mathrm{O}_{7-\delta}$ and related compounds $\mathrm{Ca}_{0.9} \mathrm{BaLaCu}_{3} \mathrm{O}_{7-\delta}, \mathrm{Ca}_{11} \mathrm{BaLaCu}_{3} \mathrm{O}_{7-\delta}$ and $\mathrm{Ca}_{0.9} \mathrm{Ce}_{0.1} \mathrm{BaLaCu}_{3} \mathrm{O}_{7-\delta}$ in order to investigate the effect of doping and non-stoichiometry at Ca-sites on the superconducting behaviour of tetragonal superconductor $\mathrm{CaBaLaCu}_{3} \mathrm{O}_{7-\delta}$. The superconducting transition temperature $\left(T_{c}\right.$ ) of $\mathrm{Ca}_{0.9} \mathrm{BaLaCu}_{3} \mathrm{O}_{7-\delta}$ is the same as that of pure $\mathrm{CaBaLaCu}_{3} \mathrm{O}_{7-\delta}(67 \pm 1 \mathrm{~K}$ ). Calcium excess compound $\mathrm{Ca}_{1.1} \mathrm{BaLaCu}_{3} \mathrm{O}_{7-\delta}$ showed an enhancement in $T_{c}$ to $72 \mathrm{~K}$ while the cerium-substituted compound $\mathrm{Ca}_{0.9} \mathrm{Ce}_{0.1} \mathrm{BaLaCu}_{3} \mathrm{O}_{7-\delta}$ showed a drop in $T_{c}$ to $43 \mathrm{~K}$. The results are explained on the basis of difference in valency between the host and the dopant ion.
\end{abstract}

Keywords. $\mathrm{CaBaLaCu} \mathrm{O}_{7-\delta}$; non-stoichiometry; cerium-doping tetragonal superconducting phase.

\section{Introduction}

Ever since the discovery of high temperature superconductivity in the $\mathrm{Y}-\mathrm{Ba}-\mathrm{Cu}-\mathrm{O}$ system (Wu et al 1987) several isovalent and aliovalent substitutions for $\mathrm{Y}$ and $\mathrm{Ba}$ were made by different groups in order to investigate the structure-property relationships in this compound. Now it is a well-documented experimental fact that pristine $\mathrm{YBa}_{2} \mathrm{Cu}_{3} \mathrm{O}_{7-\delta}$ is superconducting only in its orthorhombic phase while the tetragonal phase is an antiferromagnetic insulator. During the investigation of cosubstitution of $\mathrm{Ca}^{2+}$ for $\mathrm{Y}^{3+}$ and $\mathrm{La}^{3+}$ for $\mathrm{Ba}^{2+}$ in this system a new tetragonal superconductor $\mathrm{CaBaLaCu}{ }_{3} \mathrm{O}_{7}$ with $T_{c}$ of $80 \mathrm{~K}$ was discovered independently by two groups (Tokura et al 1988; Carim et al 1988). More recently Peng et al (1989) have observed that in the series of tetragonal superconductors $\mathrm{La}\left(\mathrm{Ba}_{1-x} \mathrm{Ca}_{x}\right)_{2} \mathrm{Cu}_{3} \mathrm{O}_{7-\delta}$ only one composition $(x=0.5)$ showed a sharp superconducting transition $\left(T_{c}\right.$ $=78.5 \mathrm{~K}$ ), and the transition became broad as one moved away from the composition corresponding to $x=0.5$. This was attributed to an ordering of the cations for the stoichiometric composition $\mathrm{CaBaLaCu}{ }_{3} \mathrm{O}_{7-\delta}$, as well as oxygen ordering in it. The structure of this compound is distinct from that of $\mathrm{LaBa}_{2} \mathrm{Cu}_{3} \mathrm{O}_{7-\delta}$ since it has been conjectured that nearly $40 \%$ of $\mathrm{Ca}$-ions occupy the $\mathrm{Y}$-sites of $\mathrm{YBa}_{2} \mathrm{Cu}_{3} \mathrm{O}_{7-\delta}$ structure (De Leeuw et al 1988). In this paper we report the synthesis and the superconducting behaviour of $\mathrm{CaBaLaCu}_{3} \mathrm{O}_{7-\delta}$ as well as the related compounds $\mathrm{Ca}_{1.1} \mathrm{BaLaCu}_{3} \mathrm{O}_{7-\delta}, \mathrm{Ca}_{0.9} \mathrm{BaLaCu}_{3} \mathrm{O}_{7-\delta}$ and $\mathrm{Ca}_{0.9} \mathrm{Ce}_{0.1} \mathrm{BaLaCu}_{3} \mathrm{O}_{7-\delta}$ to investigate the effect of dopants and non-stoichiometry at $\mathrm{Ca}$-sites.

\section{Experimental}

The samples were prepared by a precursor matrix reaction technique, which involved reacting appropriate amounts of $\mathrm{La}_{2} \mathrm{O}_{3}$ with a pre-reacted matrix (say, $\mathrm{CaBaCu}_{3} \mathrm{O}_{x}$ ) at $1253 \mathrm{~K}$ in air for $18 \mathrm{~h}$, crushing, repelletizing and annealing in oxygen environment at $1223 \mathrm{~K}$, followed by slow cooling to room temperature. 
A part of the pellet was ground for X-ray diffraction analysis, thermogravimetric analysis and A.C. susceptibility measurements, and from the remainder rectangular bars were cut for our resistivity measurements. Resistivity was measured in the standard four-probe configuration; leads attached with silver paint and samples mounted to the cold head of closed cycle helium refrigerator with Apiezon $\mathrm{N}$ grease. Temperatures monitored with silicon diode, are accurate to $\pm 0.2 \mathrm{~K}$. The temperature of the cold head was controlled by employing a Lakeshore temperature controller (model 805). Electrical resistivity was measured between 7 and $300 \mathrm{~K}$. X-ray diffraction analysis was carried out on a Phillips diffractometer equipped with copper target and a graphite-diffracted beam monochromator tuned to $\mathrm{CuK}_{\alpha}$ radiation.

\section{Results and discussion}

The room temperature X-ray diffraction patterns of all samples (figure 1) did not show any evidence of orthorhombic distortion and could be fitted into a tetragonal structure.

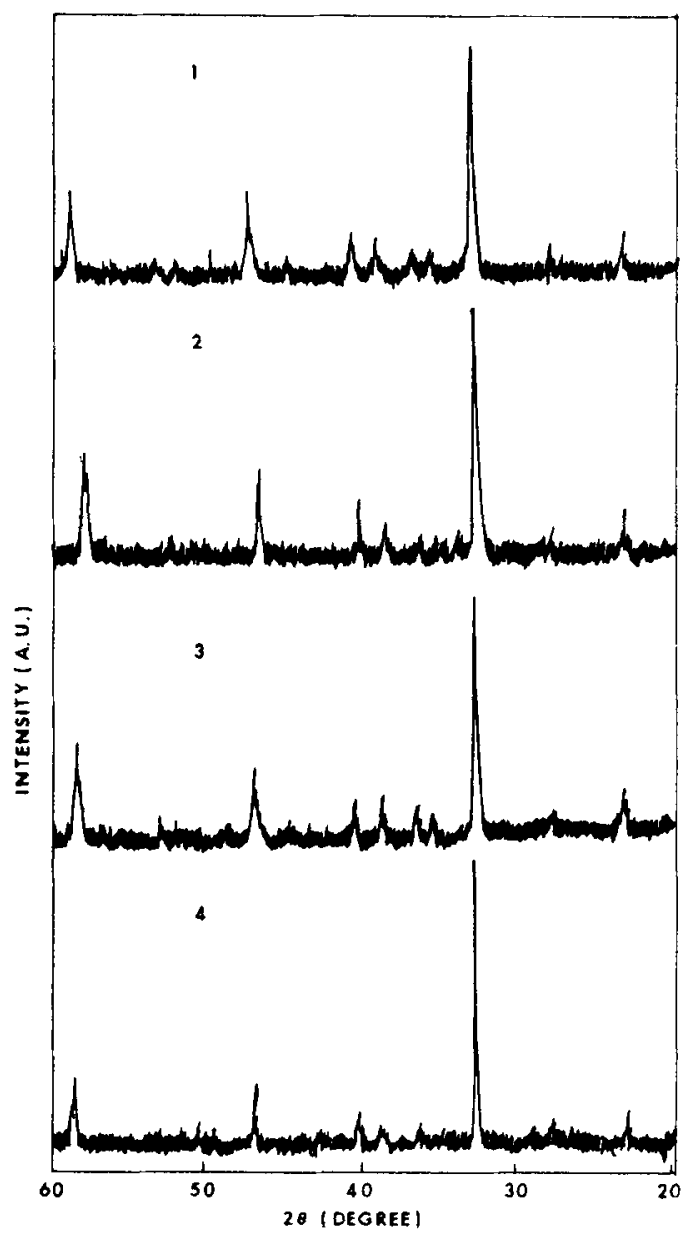

Figure 1. Room temperature $\mathrm{X}$-ray diffraction patterns of 1. $\mathrm{Ca}_{0.9} \mathrm{BaLaCu}_{3} \mathrm{O}_{7-\delta}$. 2. $\mathrm{CaBaLaCu} \mathrm{O}_{7-\delta}$. 3. $\mathrm{Ca}_{1.1} \mathrm{BaLaCu}_{3} \mathrm{O}_{7-\delta}$ and 4. $\mathrm{Ca}_{0.9} \mathrm{Ce}_{0.1} \mathrm{BaLaCu}_{3} \mathrm{O}_{7-\delta}$. 


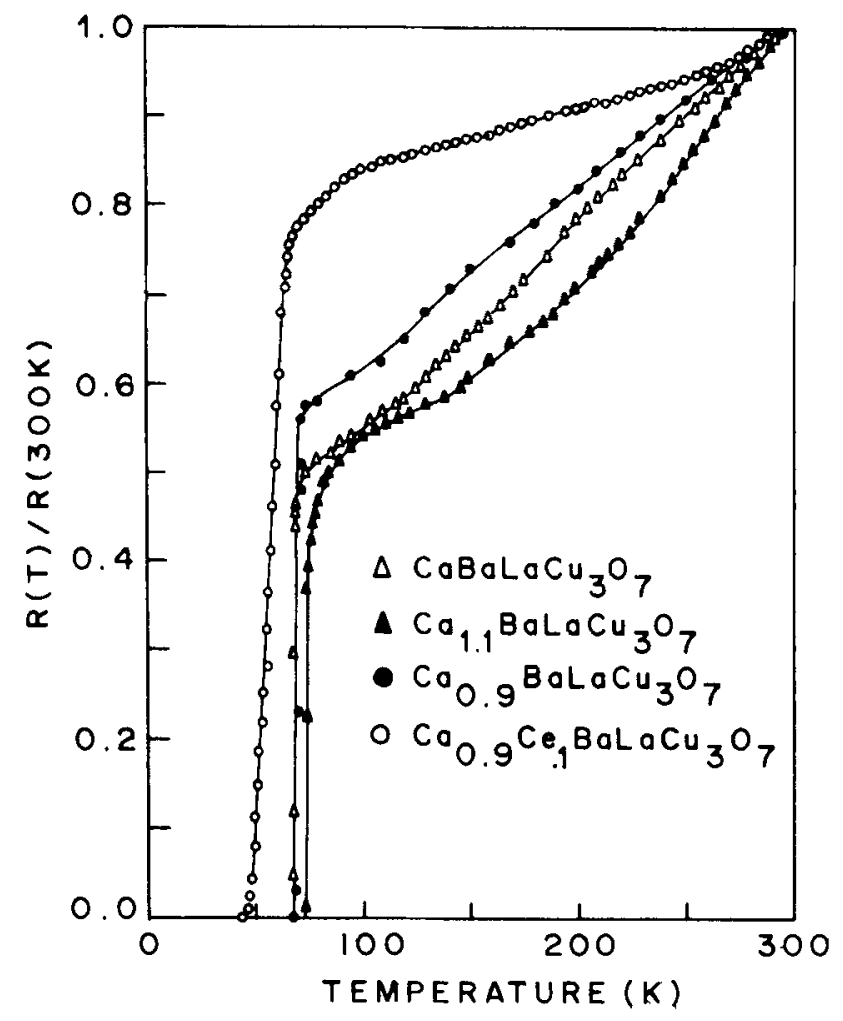

Figure 2. Normalized resistance versus temperature of pure, cerium-doped and nonstoichiometric (calcium-deficient and excess) samples of $\mathrm{CaBaLaCu} \mathrm{O}_{7-\downarrow}$.

The cell parameters for $\mathrm{CaBaLaCu}{ }_{3} \mathrm{O}_{7-\delta}$ for instance, were $a=3.87 \AA$ and $c=11.62 \AA$ in good agreement with literature. Room temperature $\mathrm{X}$-ray diffractograms of these compounds showed lines corresponding to tetragonal phase only and did not show any impurity peaks corresponding to parasitic phases. Examination of the samples under scanning electron microscope also confirmed their single-phase nature. Attempt to incorporate more than 10 at. $\%$ Ce resulted in a multiphase compound indicating the limit of solid solubility of cerium in this compound. The superconducting transition temperature for pure $\mathrm{CaBaLaCu}_{3} \mathrm{O}_{7-\delta}$ as determined by electrical resistivity (figure 2) and A.C. susceptibility is $67 \mathrm{~K}$. The $T_{r}$ value for $\mathrm{Ca}_{0,9} \mathrm{BaLaCu}_{3} \mathrm{O}_{7-\delta}$ is nearly identical to that of pure compound $\mathrm{CaBaLaCu}{ }_{3} \mathrm{O}_{7-\delta}(67 \pm 1 \mathrm{~K})$. The $\mathrm{Ce}$-doped compound $\mathrm{Ca}_{0.9} \mathrm{Ce}_{0.1} \mathrm{BaLaCu}_{3} \mathrm{O}_{7}$ showed a drop in $T_{c}$ to $43 \mathrm{~K}$ while the Ca-excess compound $\mathrm{Ca}_{1.1} \mathrm{BaLaCu}_{3} \mathrm{O}_{7}$ showed an improvement in $T_{c}$ to $72 \mathrm{~K}$. The decrease of $T_{c}$ in $\mathrm{Ce}-$ doped compound may be due to the tetravalent nature of $\mathrm{Ce}$-ion. Substitution of tetravalent $\mathrm{Ce}$ for divalent $\mathrm{Ca}$ is likely to bring down considerably the number of holes in the $\mathrm{Cu}-\mathrm{O}$ sub-band thereby depressing the $T_{c}$. However, the reason for enhancement of $T_{c}$ by incorporating excess of Ca-ions in this compound is not well understood. Probably some of these divalent $\mathrm{Ca}$-ions may be occupying trivalent La-sites thereby increasing the number of holes in the $\mathrm{Cu}-\mathrm{O}$ sub-band and $T_{c}$. Preliminary neutron diffraction profile analysis of the site occupancies of the cations in $\mathrm{CaBaLaCu}_{3} \mathrm{O}_{7-\delta}$ indicates that $\mathrm{Ca}$-ions are located at the corresponding $\mathrm{Y}$-sites in the 123-structure; with $\mathrm{La}$ and $\mathrm{Ba}$ disordered on the Ba-sites. 


\section{Conclusions}

We have synthesized in single-phase form tetragonal $\mathrm{CaBaLaCu}_{3} \mathrm{O}_{7-\delta}$ with superconducting transition temperature $T_{c}$ of $67 \pm 1 \mathrm{~K}$. Partial substitution of calcium by cerium (10 at. $\%$ ) resulted in depression of $T_{c}$ down to $43 \mathrm{~K}$ while incorporation of excess of calcium ( 10 at. \%) in the compound resulted in enhancement of $T_{\mathrm{c}}$ to $72 \mathrm{~K}$. The results have been explained on the basis of difference between the valency of the host and the dopant ion.

\section{Acknowledgement}

One of the authors (RAG) is thankful to the Program Management Board on Superconductivity of the Department of Science and Technology, Government of India, for financial support.

\section{References}

Carim A H, de Jong A F and de Leeuw D M 1988 Phys. Rev. B38 7009

De Leeuw D M. Mutsaers C A, van Hal H A M, Verweij H, Carim A H and Smoorenburg H C A 1988 Phisica C156 126

Peng J L. Klavins P K, Shelton R N, Radonsky H B. Halin P A. Bernardez L and Costantino M 1989 Phys. Ret. B39 9074

Tokura Y. Torrance J B, Haung T C and Nazzal A I 1988 Phys. Rev. B38 7156

Wu M K, Ashburn J R, Torng C J. Hor P H, Meng R L, Gao L, Huang Z J. Wang Y Q and Chu C W 1987 Phy's. Ret. Lent. 58908 